\title{
WhatsApp y Periodismo. Análisis del uso de WhatsApp en los medios de información españoles
}

\author{
FÁtIMA FARES \\ Universidad Complutense de Madrid \\ ffares@ucm.es \\ https://es.linkedin.com/in/fatimafaresmedina

\section{WhatsApp and Journalism. Analysis of the use of WhatsApp in the Spanish media}

\begin{abstract}
RESUMEN
Según los últimos datos publicados por la compañía, WhatsApp cuenta con más 1.200 millones de usuarios activos a nivel mundial. Lo más sorprendente es el ritmo de crecimiento, ya que en sólo cuatro años ha duplicado su número de usuarios. Ante este nuevo contexto, no es de extrañar que los medios de comunicación comiencen a explorar el acceso al contenido informativo desde plataformas de mensajería como WhatsApp, lo que se convierte en una oportunidad para los medios de comunicación. El presente artículo tiene la finalidad de analizar y explorar cómo esta aplicación se está utilizando en el ámbito del periodismo español y cuáles son las posibilidades que brinda para los medios de comunicación.
\end{abstract}

PALABRAS CLAVE

Periodismo digital, Innovación disruptiva, NTIC, WhatsApp, Aplicaciones mensajería, Bots, Diarios digitales, Grupos editoriales

\section{ABSTRACT}

According to the latest data published by the company, WhatsApp has over 1.2 billion active users globally. Since in only four years it has doubled its number of users. Given this new context, the media begin to explore access to information content from messaging platforms like WhatsApp, which becomes an opportunity for the media. This article aims to analyze and explore how this application is being used in the field of Spanish journalism and what are the possibilities it provides for the media.

\section{KEYWORDS}

Online Journalism, Disruptive, NTIC, WhatsApp, Messaging Applications, Bots, Digital Newspapers, Publisher Groups 


\section{Introducción}

El acceso al contenido informativo cada vez se produce más desde las redes sociales. De entre todas las redes sociales, Facebook es la plataforma que mayor tráfico proporciona a los medios de comunicación. Sin embargo, en los últimos años comienzan a aparecer otros players: Aplicaciones de mensajería. Y dentro de estas aplicaciones, WhatsApp comienza a liderar el acceso al contenido informativo. Así lo demuestra el informe anual de medios digitales de Reuters. Y es que el uso de WhatsApp para el acceso a las noticias está comenzando a rivalizar con Facebook en países como Malaysia (51\%), Brasil (46\%) y España (32\%).

En la Figura 1 observamos que Facebook sigue siendo la principal red social para acceder a las noticias, con un $47 \%$ del total de los encuestados. Pero la gran novedad este año es el crecimiento del porcentaje de los usuarios que acceden al contenido informativo a través de las aplicaciones de mensajería, que ya supone el $23 \%$ del total. Un $15 \%$ de este $23 \%$ accede al contenido informativo desde WhatsApp.

Por otro lado, este crecimiento de las aplicaciones de mensajería coincide con una ralentización del crecimiento del uso de las redes sociales para acceder a las noticias en la mayoría de los países. Y no sólo se ralentiza, sino que, tal y como refleja la Figura 2, baja en países como España (-2), Portugal (-4), Italia (-5), Australia (-6) y Brasil (-6).

En el caso español, esta bajada de dos puntos sobre el año anterior coincide con el cambio de algoritmo en Facebook, que

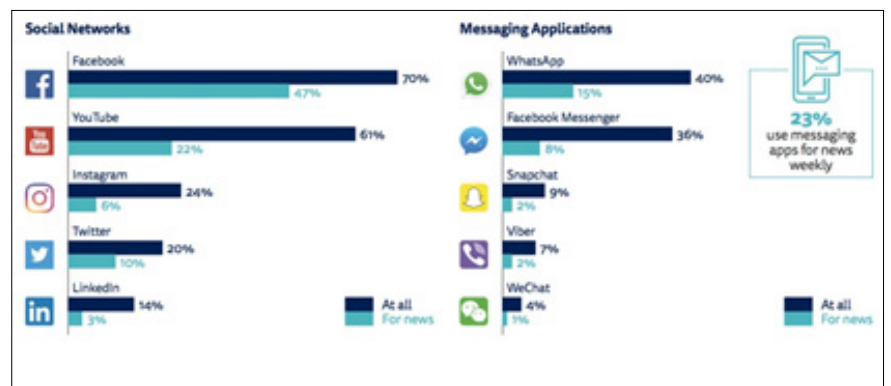

Figura 1. Consumo de noticias desde redes sociales y aplicaciones de mensajería. Fuente: Digital News Report Reuters 2017.

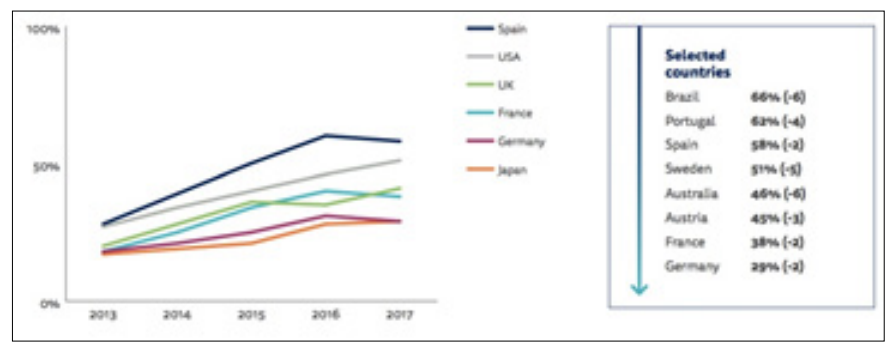

Figura 2. Evolución del acceso al consumo de noticias desde redes sociales en los últimos cinco años. Fuente: Digital News Report Reuters 2017. tuvo lugar en 2016.

Volviendo al acceso al contenido informativo a través de las aplicaciones de mensajería, el mapa cambia en función del país analizado. En España, Lidera WhatsApp y experimenta un crecimiento de ocho puntos sobre el año anterior. En la Figura 3 representamos los porcentajes por países.

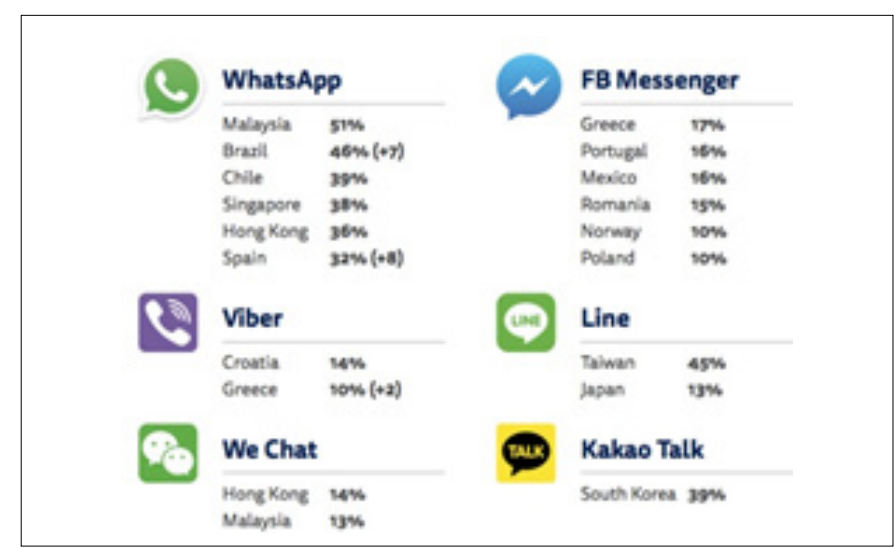

Figura 3. Top de aplicaciones para acceder al contenido informativo por países. Fuente: Digital News Report Reuters 2017.

Según los datos publicados por la compañía, WhatsApp cuenta con más de 1.200 millones de usuarios activos a nivel mundial. Aunque lo más sorprendente es el ritmo de crecimiento, ya que sólo en cuatro años duplica el número de usuarios.

Ante este panorama, creemos que el uso de WhatsApp en los medios de información general supone una oportunidad para el periodismo debido a la extensión de su uso en usuarios de todas las franjas de edades, desde los perfiles más jóvenes, hasta los más veteranos que no han pasado por la era de Internet. El presente artículo tiene la finalidad de analizar y explorar cómo esta aplicación se está utilizando en el ámbito del periodismo español y cuáles son las posibilidades que brinda a los medios de comunicación.

\subsection{Metodología del estudio}

Debido a que la historia de WhatsApp es relativamente reciente, la metodología utilizada en el presente estudio se ha centrado en la recopilación de artículos y noticias de los últimos cinco años con el objetivo de identificar las primeras experiencias de uso en los medios de comunicación a nivel mundial. Con esta información, hemos construido una base de estudio y marco teórico que nos permite centrar nuestra investigación en España.

Para acercarnos a este estudio, hemos seleccionado una muestra compuesta por los medios de comunicación de los principales grupos de comunicación españoles. En un primer momento, hemos contemplado televisiones, periódicos, radios y medios nativos. En total, la muestra inicial se compone de 87 medios de comunicación, que agrupamos en cinco categorías. La primera de ellas hace referencia a los periódicos naciona- 
les con edición impresa. En un segundo nivel, encontramos los periódicos locales y regionales con edición impresa. Los medios radiofónicos constituyen la tercera categoría, mientras que los medios televisivos la cuarta. Por último, hemos querido analizar también algunas cabeceras online de medios nativos, es decir, diarios sin edición impresa, que conforma la quinta categoría de la muestra de este estudio.

Una vez seleccionada la muestra, el primer paso ha sido realizar una segmentación entre los medios que sí han experimentado con WhatsApp en algún momento de los últimos cuatros años, ya sea como medio de difusión del contenido informativo o como medio de recepción y conversación con el lector, y los que nunca han usado este servicio.

Después, debido a que los periódicos son los que más han experimentado con esta tecnología, hemos centrado el estudio en los diarios de información general, ya que las experiencias de los medios radiofónicos se centran en su mayoría en la recepción e interacción con el lector en programas de las principales emisoras españolas. Un aspecto muy interesante, aunque hemos querido centrarnos en las experiencias de los medios de comunicación españoles como emisores más que como receptores, dado que nuestro enfoque es desde el punto de vista periodístico.

En el caso del medio televisivo, sólo encontramos un ejemplo de experiencia del uso de WhastApp como medio de difusión del contenido informativo, pero, puesto que el servicio actualmente no está operativo, y la dinámica coincide con el resto de diarios de información general, hemos decidido no profundizar en su estudio.

Con el objeto de profundizar sobre el uso de WhatsApp en los diferentes diarios con edición impresa que han sido pioneros en este uso, se han realizado cuatro cuestionarios durante el mes de septiembre de 2017. Estos cuestionarios han sido respondidos por la responsable de redes sociales de Prensa Ibérica, Fátima Martel; por el director de innovación y desarrollo editorial de medios regionales y revistas de Vocento, Fernando Belzunce; por el redactor jefe en El Confidencial, Alvaro Rigal, y, de forma conjunta, por el jefe de producto digital de El Periódico Catalunya,Francesc Pallarès, y el jefe de contenidos digitales de El Periódico Catalunya, Xurxo Martínez.

Para poder obtener una visión lo más completa posible, además de los cuestionarios, también hemos creído conveniente hacer una serie de entrevistas en profundidad. La primera de ellas se la realizamos a Antonio Gallo, CEO de Dogtrack, empresa española que ofrece tecnología social media para medios de comunicación.

Una segunda entrevista se la hemos realizado a David Varona Aramburu, experto en servicios de mensajería y profesor de la Universidad Loyola de Andalucía. Además, Varona ha sido redactor jefe de proyectos de RTVE.es, aunque actualmente está de excedencia.

Una vez recopilada toda la información, nos centramos en el análisis de lo que consideramos tres experiencias pioneras en España: Prensa Ibérica, El Diario.es y El Periódico de Catalunya. Este último, aunque actualmente no esté en uso el servicio, por su experiencia, constituye una valiosa información para todos los medios de comunicación.

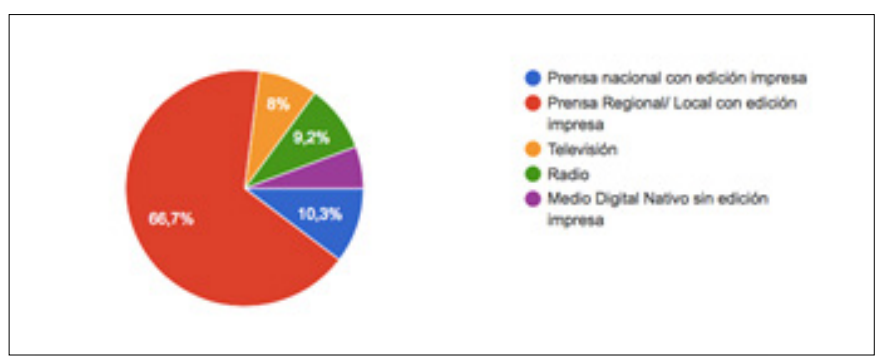

Figura 4. Resumen de la muestra analizada. Fuente: Elaboración propia a través del resumen del formulario de Google Forms.

En la Figura 4 mostramos un resumen de la muestra analizada por tipología de medio en un primer acercamiento.

Los medios de prensa escrita nacional con edición impresa analizados representan el $9 \%$ del total de la muestra. La Tabla 1 recoge los nueve medios nacionales analizados.

Los medios locales y regionales de prensa escrita representan el mayor volumen de la muestra, en concreto el 67,4\%. La explicación a este dato la encontramos en el mayor volumen de medios locales que de medios nacionales. El criterio para la selección ha sido seguir el mapa de los principales grupos de comunicación en España. La Tabla 2 recoge el desglose de los 58 medios locales y regionales analizados.

En relación a los medios nativos, suponen un 5,6\% del total de la muestra. Las televisiones representan el 7,9\%, mientras que las radios, el 9\%. En la Tabla 3 recogemos el desglose de medios analizados.

\begin{tabular}{|l|l|l|l|l|}
\hline Prisa & Unidad Editorial & Grupo Henneo & Grupo Planeta & El Economista \\
\hline El País & El Mundo & 20 Minutos & La Razón & El Economista \\
\hline Cinco Días & Marca & & & \\
\hline As & Expansión & & & \\
\hline
\end{tabular}

Tabla 1. Medios de Prensa Nacional con edición impresa analizados. Fuente: Elaboración propia 


\begin{tabular}{|c|c|c|c|c|c|c|}
\hline Prensa Ibérica & Vocento & Grupo Joly & Grupo Zeta & Grupo Godó & Grupo La Voz & Grupo Henneo \\
\hline Levante- EMV & Abc Sevilla & Málaga Hoy & $\begin{array}{l}\text { El periódico } \\
\text { de Aragón }\end{array}$ & La Vanguardia & $\begin{array}{l}\text { La Voz de } \\
\text { Galicia }\end{array}$ & Heraldo de Soria \\
\hline $\begin{array}{l}\text { La Nueva } \\
\text { España }\end{array}$ & El Correo & $\begin{array}{l}\text { Huelva Infor- } \\
\text { mación }\end{array}$ & $\begin{array}{l}\text { El Periódico } \\
\text { de Catalunya }\end{array}$ & $\begin{array}{l}\text { El Mundo } \\
\text { Deportivo }\end{array}$ & & $\begin{array}{l}\text { Diario Alto } \\
\text { Aragón }\end{array}$ \\
\hline Faro de Vigo & Diario Vasco & Diario de Sevilla & $\begin{array}{l}\text { El Periódico de } \\
\text { Extremadura }\end{array}$ & & & $\begin{array}{l}\text { Heraldo de } \\
\text { Aragón }\end{array}$ \\
\hline $\begin{array}{l}\text { La Opinión } \\
\text { de Zamora }\end{array}$ & $\begin{array}{l}\text { El Diario } \\
\text { Montañés }\end{array}$ & Diario de Cádiz & Mediterráneo & & & \\
\hline $\begin{array}{l}\text { La Opinión } \\
\text { de Tenerife }\end{array}$ & $\begin{array}{l}\text { La Verdad } \\
\text { de Murcia }\end{array}$ & Diario de Jérez & Córdoba & & & \\
\hline La Provincia & Ideal & Europa Sur & $\begin{array}{l}\text { La Crónica } \\
\text { de Badajoz }\end{array}$ & & & \\
\hline Regió 7 & Hoy & $\begin{array}{l}\text { El Día de } \\
\text { Córdoba }\end{array}$ & Otros & & & \\
\hline $\begin{array}{l}\text { Mallorca } \\
\text { Zeitung }\end{array}$ & Sur & Granada Hoy & $\begin{array}{l}\text { Adelantado } \\
\text { de Segovia }\end{array}$ & & & \\
\hline $\begin{array}{l}\text { La Opinión } \\
\text { Coruña }\end{array}$ & La Rioja & $\begin{array}{l}\text { Diario de } \\
\text { Almería }\end{array}$ & $\begin{array}{l}\text { La Gaceta de } \\
\text { Salamanca }\end{array}$ & & & \\
\hline Diario de Ibiza & \begin{tabular}{|l|} 
El Norte de \\
Castilla \\
\end{tabular} & & Diario de Jaén & & & \\
\hline $\begin{array}{l}\text { La Opinión } \\
\text { de Málaga }\end{array}$ & El Comercio & & Canarias 7 & & & \\
\hline $\begin{array}{l}\text { La Opinión } \\
\text { de Murcia }\end{array}$ & Las Provincias & & Diario de Avisos & & & \\
\hline Diari de Girona & La Voz de Cádiz & & $\begin{array}{l}\text { La Voz de } \\
\text { Almería }\end{array}$ & & & \\
\hline Superdeporte & & & Última Hora & & & \\
\hline \multicolumn{7}{|l|}{ Empordá } \\
\hline \multicolumn{7}{|l|}{$\begin{array}{l}\text { Diario } \\
\text { Información }\end{array}$} \\
\hline $\begin{array}{l}\text { Diario de } \\
\text { Mallorca }\end{array}$ & & & & & & \\
\hline
\end{tabular}

Tabla 2. Medios de Prensa local con edición impresa analizados. Fuente: Elaboración propia

\section{WhastApp, una nueva vía de conversación y difusión para los medios}

\subsection{La primera experiencia como medio de recepción}

La primera experiencia de un medio de comunicación en WhatsApp la encontramos en Brasil, de la mano del periódico brasileño Extra. Fue en marzo de 2013 cuando el periodista Fábio Gusmão, redactor online del periódico, comienza a observar el gran potencial que la aplicación podría tener para el periodismo. Tras tres meses de observación, el 24 de junio de 2013 (EXTRA, 2013) se lanza la primera experiencia receptora utilizando WhatsApp, es decir, una vía de comunicación bidireccional con el medio de comunicación utilizando la aplicación de mensajería para ello. Hasta el momento, este nuevo canal suponía una estrategia totalmente inédita en los medios de comunicación, no sólo brasileños, sino a nivel mundial.

Este proyecto estaba basado en el uso de la aplicación como medio de recepción y conversación con el lector. Sólo 48 horas

\begin{tabular}{|c|c|c|}
\hline Medios Nativos & Radio & Televisión \\
\hline Diario Crítico & Cadena Ser & La Sexta \\
\hline El Español & Cope & TVE \\
\hline El Confidencial & Radio Nacional & Intereconomía \\
\hline Eldiario.es & Onda Cero & Telecinco \\
\hline Huffpost & Europa FM & Cuatro \\
\hline La Voz de Asturias & Los 40 Principales & Antena 3 \\
\hline & Intereconomía & Telemadrid \\
\hline & Radio Marca & \\
\hline
\end{tabular}

Tabla 3. Resumen de medios nativos, radios y televisiones analizados. Fuente: Elaboración propia

después del lanzamiento, más de 350 personas ya enviaron material, tanto denuncias, como avisos de temas informativos en los que poder abrir nuevas vías de investigación, y que a ningún otro medio de comunicación le podrían haber llegado por las "vías tradicionales" (Flamarich, 2014).

Este fue el momento en el que nacía el uso de WhatsApp como medio de interacción y conversación con el lector, en el que sólo era necesario un teléfono inteligente, una línea de telé- 
fono con conexión de datos y una comunicación bidireccional constante.

En poco más de año, conseguimos reunir más de 26.000 personas. Recibimos más de un millón de mensajes, más de 50.000 fotos, 2.000 videos, más de 1.800 audios, elaboramos más de 600 reportajes y centenares de casos exclusivos (Gusmão, entrevista en Ramalho, 2014).

Tres años después de esta experiencia, este servicio ya contaba con más de 70.000 suscriptores, que contribuyeron a la publicación de cerca de 3.800 publicaciones. Tal fue la repercusión del servicio, que el proyecto de WhastApp del periódico Extra se convirtió en finalista en los Premios de Medios Digitales de Latinoamérica, de WAN-IFRA. David Varona reflexiona:

Las aplicaciones de mensajería privada, están ocultando buena parte de la conversación que antes estaba en Twitter o Facebook. El gran reto de los medios de comunicación españoles es buscar la forma de reconducir esta conversación a entornos más abiertos, o perderemos parte de esa riqueza que quedará atrapada en las aplicaciones.

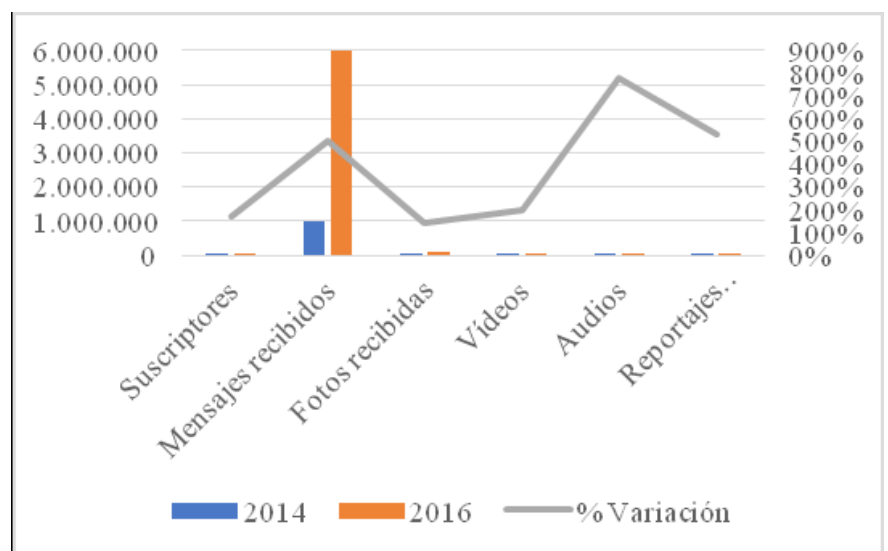

Figura 5. Evolución del material recibido en el servicio de WhatsApp de Extra. Fuente: Elaboración propia con los datos públicos.

En la Figura 5 mostramos la evolución dos años después de las primeras cifras publicadas. La línea gris representa el ritmo de crecimiento del número de suscriptores, mientras que el diagrama de barras representa la comparativa de los mensajes recibidos, fotos, vídeos, audios y reportajes creados gracias al material recibido a través de este servicio en 2014 y 2016.

En comparación con el resto del material recibido, en la Figura 5 llama especialmente la atención el crecimiento de las notas de audio, con un $778 \%$ por encima de 2014 . Estas cifras ponen de manifiesto que las notas de voz, junto con los mensajes de texto, son los formatos preferidos para el envío de material para la audiencia de Extra.

Además de la facilidad para la interacción con el lector, el gran impacto de este servicio para el periodismo está en las nuevas historias y relatos que se construyen gracias a este contenido generado por el usuario, incluso gracias a la conversación que se genera con el medio. Sirva de ejemplo como crece un 533\% en sólo dos años el número de reportajes creados con este material. Es decir, pasa de los 600 a los 3.800 reportajes. Para entender el impacto de esta cifra en dos años, cabe señalar que supone una media de 5,2 historias nuevas cada día gracias a esta vía de conversación con el lector. Y como señala el impulsor de esta iniciativa, Fábio Gusmão, "no aprovechamos ni siquiera un 5\% de lo que nos llega porque es imposible".

Para profundizar en las cifras, en la tabla Tabla recogemos los datos del servicio de WhatsApp de 2014 y 2016, con el cálculo del porcentaje de crecimiento de los años posteriores al lanzamiento del servicio.

\begin{tabular}{|l|c|c|c|}
\hline WhastApp Extra Brasil & 2014 & 2016 & $\begin{array}{c}\% \text { Varia- } \\
\text { ción }\end{array}$ \\
\hline Suscriptores & 26.000 & 70.000 & $169 \%$ \\
\hline Mensajes recibidos & 1.000 .000 & 6.000 .000 & $500 \%$ \\
\hline Fotos recibidas & 50.000 & 120.000 & $140 \%$ \\
\hline Vídeos & 2.000 & 6.000 & $200 \%$ \\
\hline Audios & 1.800 & 15.800 & $778 \%$ \\
\hline $\begin{array}{l}\text { Reportajes creados con } \\
\text { ese contenido }\end{array}$ & 600 & 3.800 & $533 \%$ \\
\hline
\end{tabular}

Tabla 4. Comparativa de las cifras del servicio de WhatsApp del Extra de 2014 con 2016. Elaboración propia

A pesar de la gran acogida, este servicio también tenía sus carencias. Una de las principales limitaciones del uso de WhatsApp como medio de conversación con los lectores, es que una misma cuenta de usuario no podía ser gestionada por varias personas o dispositivos a la vez. Debido a esta limitación, los redactores de Extra se turnaban el teléfono para leer y responder a los mensajes. "No es muy práctico", admitía Gusmão. Para superar esta carencia y dar la opción a que más periodistas pudieran participar en el proceso, se instalaron dos televisores en la redacción. De esta forma, era más probable que los mensajes urgentes no pasaran desapercibidos.

Otra de las barreras con las que se toparon, fue el temido bloqueo de WhatsApp. "Ya hemos sido bloqueados dos veces. Hoy formamos parte de una lista vip. Mi objetivo es llegar a 100.000 usuarios a finales de año. Lo habríamos alcanzado ahora si no fuera por los problemas de tecnología", señalaba Fábio Gusmão en la entrevista publicada por Knight Center for Journalism in the Americas en $2016^{4}$. 
Y es que los problemas con la aplicación se remontan a sus inicios. Tan sólo unos meses después de su lanzamiento, en diciembre de 2013, WhatsApp les bloqueó el servicio. Según explicó Gusmão al Kinght Center, contactó directamente con el CEO de WhastApp, Jan Koum, y consiguió que les restablecieran el servicio pero, años más tarde, se les volvió a bloquear otra de las líneas que utilizaban. ¿Por qué se bloqueaba el servicio? La explicación la encontramos en el número de mensajes que se envían desde el mismo número de teléfono. Si el volumen es muy elevado, el sistema lo interpreta como spam y bloquea el acceso.

Pero esta experiencia tuvo un impacto mucho mayor para el periodismo. Por primera vez WhatsApp fue consciente de su uso para fines periodísticos. Las únicas declaraciones de la compañía en relación al uso de la aplicación con fines periodísticos, las hizo públicas Gusmão. En un principio, los representantes de la aplicación aseguraron que el servicio de mensajería con fines periodísticos no era el foco de la empresa, y que no preveían que a corto plazo se abriera un canal para los medios de comunicación. Sin embargo, parece que esta experiencia despertó interés en los representantes de la aplicación. Y es que Gusmão aseguró que fue contactado por la empresa para que explicara cómo la Redacción estaba utilizando la aplicación, e incluso le preguntó si tenían interés en pagar por un servicio personalizado. Este repentino interés nos deja ver que, aunque la aplicación no fue concebida para el uso periodístico, puede que en un futuro (no muy lejano) WhatsApp levante las limitaciones a los medios de comunicación. Ya ha dado el primer paso con la posibilidad de verificar las cuentas ${ }^{5}$ de las empresas, lo que llaman WhatsApp Bussiness.

Con el éxito de Extra, otros medios de comunicación en Brasil, como Folha de São Paulo, Estadão, Zero Hora, CBN y SBT, comenzaron a usar WhatsApp. Es lo que tienen las experiencias en los medios de comunicación. Si un grupo mantiene un servicio, automáticamente otros medios de comunicación comienzan a experimentar con él. Es llamado efecto dominó.

Pero el medio brasileño dio un paso más para desmarcarse. Un año después de lanzar el servicio de interacción con la audiencia, el 3 de junio de 2014, Extra creó la primera red de intercambio entre periodistas, la Red Narcosul (EXTRA, 2014). Esta segunda experiencia se centró en conectar a periodistas de todo el continente que cubrían el crimen organizado en América Latina. El objetivo era intercambiar información, ideas e incluso hacer preguntas que ayudaran a la investigación sobre el tráfico de drogas, el lavado de dinero, la trata de personas o la evasión fiscal. Ésta es la primera experiencia pública colaborativa de los medios de comunicación utilizando WhatsApp. Algo que sin duda abre nuevas vías para trabajos colaborativos periodísticos.

\subsection{El medio como emisor, la experiencia de la BBC}

La primera experiencia de un medio de comunicación que utiliza la aplicación como emisor y receptor de información, la encontramos un año más tarde del lanzamiento del servicio del diario Extra. En 2014 la BBC comienza sus experimentos usando las aplicaciones de mensajería instantánea. Y lo hacen con dos pilotos: BBC News India y BBC Hausa BBM en Nigeria.

Detrás de estos dos proyectos encontramos varias reflexiones que el desarrollador de aplicaciones de BBC World Service and Global News, Trushar Barot, comparte en su blog (Barot, 2014). Para Barot, la mayoría de las aplicaciones de mensajería son mucho más que aplicaciones de conversación. Son canales sociales, ya que las personas no sólo envían mensajes de texto gratis, también utilizan estas aplicaciones para organizar sus vidas mediante la interacción con sus contactos. Cada vez son más utilizadas para compartir imágenes y vídeos virales, pero también para compartir sus propias noticias. Incluso hablaba de lo que podríamos consideran como el mayor de los impulsores: La observación directa del uso. Y es que narraba un caso de uso de WhatsApp por parte de usuarios que no sabían leer ni escribir en la India, pero que utilizaban la aplicación para compartir imágenes. Algo que sin duda democratiza el uso de la aplicación e invita a explorar nuevas fórmulas de comunicación accesibles para todos los segmentos de población.

Para el proyecto piloto de la cobertura de las elecciones de la India, la cadena utilizó la plataforma de WhatsApp. El procedimiento fue invitar a los lectores (BBC Media Center, 2014) a que se suscribieran al servicio agregando el número de teléfono de la BBC. A partir de ese momento, los usuarios recibían las alertas informativas en inglés y en hindi.

En relación al segundo proyecto, BBC Hausa BBM en Nigeria [http://www.bbc.com/hausa], Llevada a cabo en la plataforma BBM de Blackberry, el procedimiento fue similar. La cadena invitaba a suscribirse a un servicio de alertas informativas con un máximo de cinco alertas al día. El contenido compartido estaba estratégicamente seleccionado para ser consumido en dispositivos móviles. La elección de este proyecto no fue casualidad. La explicación la encontramos en el tráfico que recibía el sitio web desde dispositivos móviles. El 96\% de su tráfico lo recibía en la versión móvil. Para entender esta cifra, conviene recordar que esta experiencia se llevó a cabo en 2014.

Con estos dos pilotos la BBC se convertía en el primer medio de comunicación en experimentar con el contenido editorial pensado para las plataformas de mensajería. En el piloto de la cobertura de las elecciones de la India, se mandaron contenidos de infografías del mapa electoral e imágenes de los acontecimientos del día, aunque el aspecto más destacado es que se experimentó con el uso de los emoticonos en la redac- 
ción de las alertas. Algo totalmente disruptivo hasta la fecha, e incluso impensable para un medio de comunicación pero, tal y como señala el propio Trushar Baro, en términos de interacción, el contenido con emoticonos fue el que mejor funcionó.

Al igual que ya pasó con la experiencia del periódico Extra, la experiencia con WhatsApp complicó mucho este proyecto, ya que por entonces la aplicación no tenía versión de escritorio y tampoco ofrecía ninguna estadística más allá de saber el número de suscriptores en cada una de las listas de difusión. Es por ello que todo el proceso de creación de contenido, publicación y participación lo realizaron desde el dispositivo móvil. Esto se tradujo en un mayor tiempo de dedicación, aunque también fue la plataforma que mayor engagement generó con la audiencia.

Respecto al número de alertas, a medida que se acercaban las elecciones, la frecuencia de los envíos aumentó hasta llegar a 20 artículos en el día. "La respuesta de los suscriptores fue muy positiva. Muchos dijeron que les parecía que era una experiencia más personalizada. También les gustó la inmediatez de tener el contenido directamente en su teléfono, aunque demandaba poder elegir qué contenido recibían", señala Trushar Barot en su blog.

A pesar de estas limitaciones, debido a la gran acogida de este servicio, Trushar Barot decidió seis meses más tarde volver a utilizar esta aplicación para el proyecto BBC Ebola Service en África Occidental (Barot, 2015). El 16 octubre del 2014 lanzaron una línea para seguir las actualizaciones sobre el tema en el que el contenido editorial se mandó en inglés y en francés. Respecto al formato, se mandaron tres tipos: Mensajes de texto, imágenes y notas de voz cortas. Se decidió no usar fragmentos de vídeo porque el peso de los archivos podría ser demasiado elevado para los límites de datos de los suscriptores. Tampoco se quiso hacer spam, por lo que se publicó un máximo de tres artículos al día. Lo sorprendente de esta experiencia es que no utilizaron ningún enlace que derivara a la página web de la BBC. "No publicamos ningún enlace a nuestro sitio web", apunta Barot en el blog en el que cuenta su experiencia. Según concluye, fue una experiencia muy enriquecedora, ya que las dudas del lector les hacían plantearse nuevos temas informativos y aspectos que no habían contemplado en un primer momento. El resultado fue 20.000 suscriptores (Frankenhauser, 2015), la mayoría de África occidental. Este dato refleja la función de servicio público que realiza este tipo de coberturas a través de la aplicación de WhatsApp. Como dato decir que este proyecto fue finalista en la categoría de Servicio Público en los Premios de Periodismo Online. Barot concluye: "Creo que el modelo colaborativo que surgió alrededor de este proyecto proporcionará es una valiosa información para la plantilla de la BBC en la cobertura y la contribución a las crisis humanitarias en el futuro".

Y no sólo para la plantilla de la BBC. Con esta experiencia vemos una clara aplicación del servicio para reforzar el con- cepto del periodismo de servicio gracias a la interacción con la audiencia, enriqueciendo los enfoques y reforzando el concepto de servicio. En definitiva, un periodismo útil y necesario para el ciudadano.

Con estas experiencias, la BBC abrió camino a otros medios televisivos que se sumaron a explorar las posibilidades de WhatsApp. Es el caso de Channel 4, quien comenzó a usar la aplicación para la cobertura de la histórica votación de independencia de Escocia. Así lo anunciaba el 13 de noviembre de 2014 (Channel 4 News, 2014).

\subsection{WhatsApp como canal para la difusión en los periódicos y diarios online}

Hasta el momento, hemos recogido experiencias relacionadas con la recepción de los mensajes a través de la plataforma, así como las primeras experiencias en coberturas concretas como medios emisores en televisión. Ahora bien, ¿cuándo se lanzó el primer servicio del medio como emisor en los diarios de información general?

El primer medio impreso en utilizar WhatsApp como servicio emisor de alertas informativas de manera continuada fue el Oxford Mail, un periódico local del Reino Unido. Este periódico lanzó el servicio de alertas el 23 de junio de 2014 . El lector se suscribía a un número de teléfono mandando previamente un WhatsApp indicando su nombre, apellido y la temática que prefería recibir: Boletín informativo, información deportiva o ambos. Al principio realizaba tres envíos diarios: A las 07:00 horas, a las 17:00 horas y a las 23:00 horas, cada uno con una media de 6 noticias. En el envío de la mañana además, incluían la imagen de la portada del periódico de ese día. Actualmente sólo realizan dos envíos: mañana y tarde. Para introducir las urls de las noticias incluían un acortador con el objetivo de que

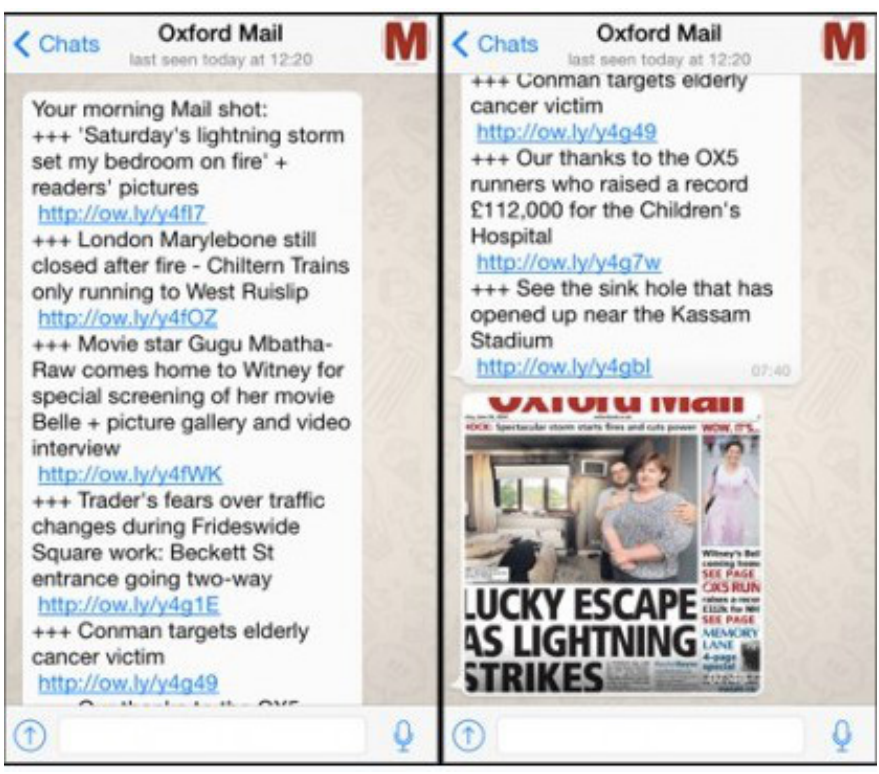

Figura 6. Capturas del envío de las alertas del servicio de WhastApp del Oxford Mail. WhatsApp Oxford Mail 
visualmente fuera más atractivo el mensaje y poder medir el tráfico. Los envíos se realizaban a través de listas de difusión, con un máximo de 256 contactos por lista, y obligaban al lector a guardar en sus contactos el número del Oxford Mail para asegurarse la recepción de los boletines y evitar ser bloqueados por WhastApp por spam. Esta experiencia y metodología es importante porque marcará el rumbo del uso de la aplicación para envíos de boletines informativos en los periódicos y diarios online. En la Figura 6 observamos uno de los primeros envíos del Oxford Mail.

Sobre esta experiencia, el propio promotor del proyecto, Jason Collie, señalaba que el porcentaje de conversión en tráfico real era entre cuatro y cinco veces más que el de la newsletter que enviaban por correo, y entre seis y siete veces más que el tráfico recibido desde Twitter. Además, señalaba que este proyecto superó sus expectativas, tanto en tráfico recibido como en interacción del lector. Y es que, a diferencia de lo que ocurrió en la experiencia de la BBC, sí que se pusieron el objetivo de quinientos suscriptores en el primer semestre, y sólo seis meses después, el Oxford Mail ya contaba con 1.265 suscriptores (Sandeman, 2015).

En octubre de 2014 damos un salto hacía Perú de la mano del periódico El Comercio, que comienza un servicio, tanto como medio de difusión como medio de recepción siguiendo un modelo similar al Oxford Mail.

En los medios nativos, ProPublica, el periódico fundado en 2008 por Paul Steiger, ex jefe de redacción de The Wall Street Journal, lanza una experiencia el 17 de noviembre de 2014. En este proyecto (Parris, 2014), T. Christian Miller, periodista que lideró el trabajo de investigación sobre la guerra civil de Liberia (Miler y Jones, 2014), fue la persona responsable de extender sus investigaciones a la conversación con los lectores en la aplicación de WhatsApp. "Éste es el futuro para la información y para el entretenimiento, y nadie sabe usarlo tan bien como los jóvenes", declaraba el fundador de ProPublica en una entrevista concedida a El Mundo (Rodríguez, 2016) cuando hacía referencia al teléfono móvil. Y no sólo los jóvenes, ya que, como señala David Varona, profesor de la Universidad de Loyola de Andalucía, en la entrevista personal, "las aplicaciones de mensajería permiten acceso a nuevos públicos, especialmente a bolsas de personas de edad avanzada que no utilizan internet".

El 5 de agosto de 2015 encontramos al primer medio venezolano en implementar el servicio de WhatsApp: Efecto Cocuyo. (Efecto Cocuyo, 2015). Y lo hace como medio de recepción y comunicación directa con la ciudadanía. Quizás el dato más significativo de este servicio es que contó con la ayuda del periodista brasileño Fabio Gusmão, pionero en Latinoamérica en la instrumentación de esta aplicación con fines periodísticos y cuya experiencia.

\section{El uso de WhatsApp en España}

Respecto al uso de WhatsApp en los 87 medios de comunicación analizados en este estudio, encontramos que el 41,6\% del análisis de la muestra sí que han experimentado con la aplicación en algún momento en los últimos cuatro años, un porcentaje relativamente elevado que demuestra el interés de dicha aplicación para los medios españoles.

La primera experiencia en España la encontramos en el medio televisivo. Fue el 11 de junio de 2014, con motivo de la cobertura del mundial de fútbol, cuando el programa deportivo Punto Pelota, del grupo Intereconomía, lanza el primer piloto. El funcionamiento de este servicio era darse de alta para recibir las noticias sobre la cobertura del mundial. Parece que el proyecto tuvo una buena acogida porque, tres días después, el 14 de junio de 2014, el grupo extiende el servicio a Radio Intereconomía, convirtiéndose así en la primera experiencia en la radio de un medio de comunicación como emisor. En las Figuras 7 y 8 recogemos las creatividades de autopromoción del servicio.

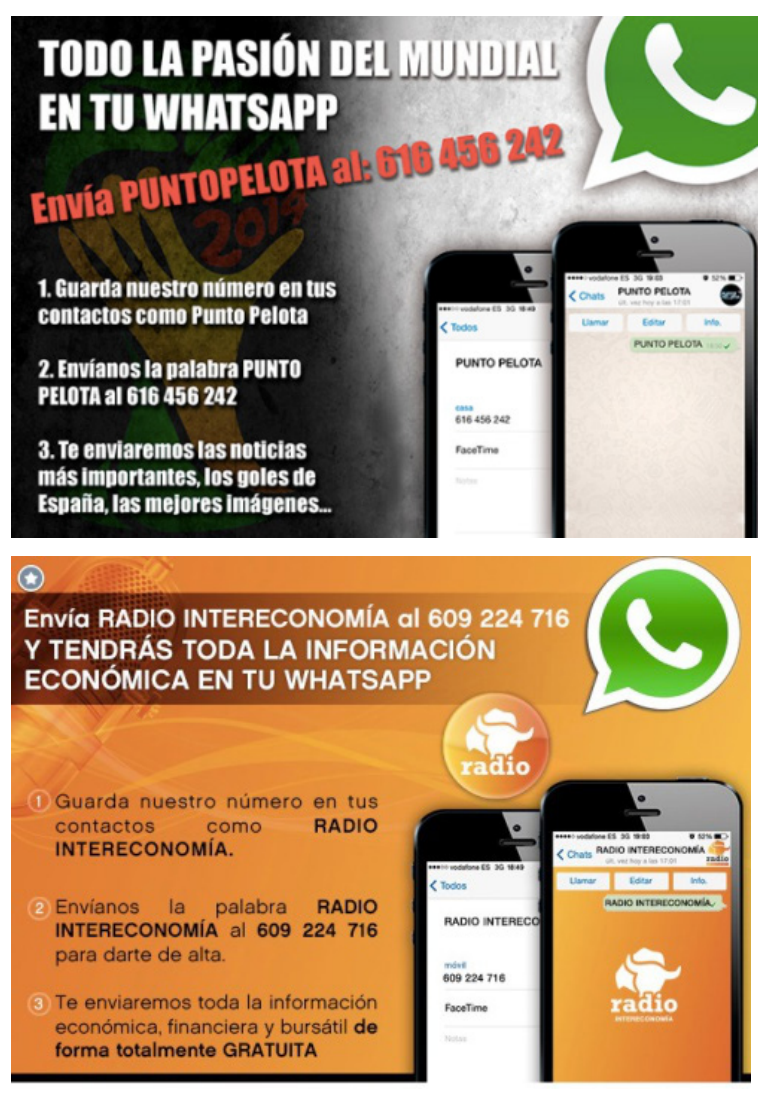

Figuras 7 y 8 . Creatividades originales de autopromoción del servicio de alertas de las primeras experiencias piloto en España. Intereconomía.

A partir de este momento, el uso de WhatsApp en los medios de comunicación españoles comienza a ser frecuente. Según muestra la Figura 9, el 2016 es el año donde mayores experiencias se llevan a cabo. 


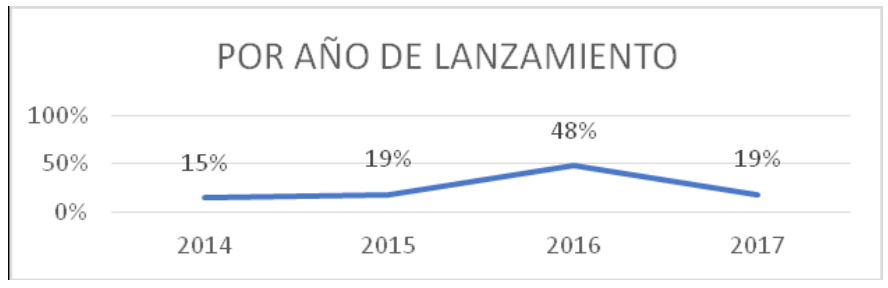

Figura 9. Porcentaje de medios de comunicación por año de lanzamiento de las primeras experiencias del uso WhatsApp en España. Elaboración propia.

\subsection{Las primeras experiencias en los diarios españoles}

En los medios impresos y diarios online, el primer uso en España aparece vinculado al grupo Vocento. Y aparece el 6 de noviembre de 2014 de la mano del periódico La Rioja, que lanza el canal de WhatsApp como medio de interacción con los lectores mediante la comunicación del lector con la redacción. Cuatro meses más tarde aparece la primera experiencia de un periódico español en usar WhatsApp como medio de difusión del contenido informativo desde la redacción hacia el lector. Y lo hace de la mano de Prensa Ibérica, cuando el 26 de febrero de 2015 Diario de Mallorca, también otro periódico local, comunica la apertura del nuevo canal para la recepción de contenido informativo de la redacción del periódico. No es casualidad que estas dos experiencias aparezcan en medios con cobertura local, ya que el $34 \%$ de los medios locales analizados han usado WhatsApp en los últimos cuatro años, mientras que sólo el $21 \%$ de los medios nacionales lo han hecho. Así lo reflejamos en la Figura 10.

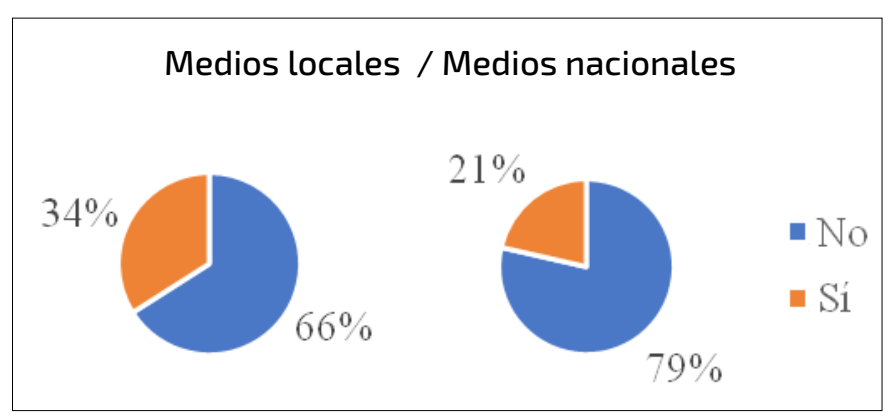

Figura 10. Porcentaje de periódicos locales y nacionales que sí han utilizado WhatsApp en los últimos 4 años. Elaboración propia.

Volviendo al servicio de Diario de Mallorca, el procedimiento para darse de alta recuerda al utilizado en el Oxford Mail. El primer paso era agregar el número de teléfono del diario a la agenda de contactos; el segundo, mandar la palabra "Alta" junto con el nombre y el apellido. Acto seguido, el lector recibía un mensaje de bienvenida en el que se insertaba también la política de privacidad y opciones de baja en el servicio. El proceso de envío de alertas se realizaba también a través de listas de difusión, con las limitaciones que conlleva la creación de una lista nueva por cada 256 contactos nuevos.

Días después, el 2 de marzo de 2015, arranca el lanzamiento del servicio de alertas informativas de Diario Información. A partir de este momento, Prensa Ibérica comienza un piloto que alcanza la madurez en febrero de 2016 con el lanzamiento del servicio en el resto de periódicos del grupo: Levante, el 21 de febrero de 2016; Faro de Vigo, el 28 de febrero de 2016; La Nueva España, el 26 de abril de 2016; La Opinión de Murcia, el 3 de mayo de 2016; La Provincia, el 5 de junio de 2016; La Opinión de Zamora, el 7 de junio de 2016; La Opinión de Málaga, el 20 de junio de 2016; Mallorca Zeitung, el 6 de octubre de 2016, Diari de Girona, el 22 de mayo de 2017 y Diario de Ibiza, el 31 de mayo de 2017.

Actualmente sólo quedan dos periódicos del grupo (Regió 7 y La Opinión de Tenerife) sin el servicio o fecha de planificación del mismo, ya que el lanzamiento en La Opinión de Coruña, Superdeporte y Empordá está planificado para este mes de octubre, lo que demuestra el grado de madurez de la utilización de este canal en Prensa lbérica.

Sobre el impacto del uso de WhatsApp en los medios de información españoles, citamos un fragmento extraído de la entrevista en profundidad realizada a David Varona, profesor en la Universidad de Loyola de Sevilla, que recoge a la perfección las ventajas competitivas que este servicio tiene para los medios de comunicación.

Me parece que empaquetar contenidos de forma que puedan ser consumidos en estos entornos es una gran ventaja competitiva: se accede a un entorno de utilización masiva donde está la gran mayoría del público y sin necesidad de que se instalen nuevas apps; se ofrecen contenidos de internet en un entorno seguro, sin tener que navegar, sin utilizar un ordenador o una tablet; se simplifican notablemente los desarrollos informáticos; se genera una nueva narrativa dialógica que emplea, además, las ventajas de la inteligencia artificial y/o el machine learning; se consigue una enorme cantidad de usuarios, que es valiosa en términos de CRM... Y, sobre todo, al acceder a públicos que usan WhatsApp pero no Internet, como las personas mayores, se cierra la brecha digital.

\subsection{Vocento}

Respecto a Vocento, después de la primera experiencia del periódico La Rioja como medio de recepción de contenido del lector, la siguiente la encontramos el 24 de mayo de 2016, fecha en la que se lanza el servicio de alertas del periódico Las Provincias, esta vez como medio de difusión de contenidos informativos. A partir de esta fecha, se suman otros periódicos del grupo: Diario Sur, el 30 de agosto de 2016; La Verdad de Murcia, el 17 de marzo de 2017 y El Comercio el 21 de abril de 2017. "Esta realidad es compleja en Vocento, porque hay periódicos que no lo utilizan y otros que sí. Dentro de los que 
lo utilizan, Sur, La Rioja o El Comercio, por ejemplo, lo utilizan para enviar noticias. Las Provincias también. Hay otros medios en proceso de utilizarlo", señala Fernando Belzunce, director de innovación y desarrollo editorial en medios regionales y revistas de Vocento.

Actualmente Vocento ofrece el canal de WhatsApp en cinco de sus trece cabeceras, de las cuales cuatro coinciden en las ubicaciones geográficas donde Prensa Ibérica tenía cabecera y ya estaba presente el servicio. Este aspecto nos hace reflexionar sobre la posibilidad de que un impulsor del uso de WhatsApp con fines periodísticos podría ser la adopción del servicio por otros medios de comunicación presentes en el mismo territorio. Belzunce concluye:

Hasta ahora WhatsApp ha sido una vía más. Interesante por la experimentación y por la relación de cercanía con la audiencia, pero no importante en términos de tráfico, audiencia, etc... Es probable, y así lo contemplamos, que, en un periodo corto de tiempo, a medida que evolucione la plataforma, sí pase a ser un canal que merezca una mayor atención, pero ahora mismo es comprensible que haya medios que aún no hayan experimentado con WhatsApp. Así como Facebook o Twitter son plataformas muy maduras (Twitter no aporta mucho tráfico, pero sí aporta otras ventajas, como notoriedad, influencia, presencia en el debate...) a WhatsApp aún le falta un cierto recorrido para los medios (se entiende en televisión y radio, como receptores de contenido, etc...).

Y así es, el uso de WhatsApp en los medios españoles no se puede medir en términos de tráfico, en gran medida por los problemas de opacidad en la medición de la información distribuida en la plataforma. Además de las complicaciones que supone el agregar uno a uno de forma manual los contactos al servicio. Antonio Rull, responsable de marketing y audiencias en Eldiario.es lo resume muy bien: "Si quieres castigar al community manager de tu empresa o medio di las palabras mágicas: Vamos a integrar WhatsApp". Seguro que esta expresión a más de uno le arrancará una media sonrisa, ya que las experiencias de uso de la aplicación con grandes audiencias ponen a prueba la paciencia de la redacción.

\subsection{Los medios nacionales}

Antonio Rull narra en primera persona la que constituye la primera experiencia de un diario nacional nativo en el uso de WhastApp con fines periodísticos. Fue el 22 de marzo de 2015 en Eldiario.es. Como ya ocurriera en la experiencia de la BBC, este medio pone en marcha con motivo de las elecciones autonómicas en Andalucía el canal de WhatsApp para seguir la cobertura de las elecciones en tiempo real.

Durante la jornada electoral, WhatsApp pasó a ser una herramienta más a tener en cuenta durante el día, como otras redes sociales. Mandamos mensajes a 2.600 personas distribuidas en 17 listas de difusión diferentes. Se utilizó un lenguaje específico para WhatsApp, diferente, por ejemplo, al que se utiliza para Twitter y Facebook. El ritmo de publicación fue poco intensivo, ya que el objetivo que nos marcamos para esta ocasión no era la generación de una audiencia masiva desde la aplicación, sino la generación de una nueva comunidad de consumo de información, señala Antonio Rull en su blog (Rull, 2015).

Para Rull el riesgo es que, debido a la alta carga de trabajo, sólo se actualice cuando esté el responsable de redes sociales. Además, califica (con gran acierto) la gestión como "un poco rudimentaria". Pero lo cierto es que Eldiario.es volvió a usar el servicio para las elecciones del 20 de diciembre de 2015 (eldiario.es, 2015). En esta ocasión decidieron dar un paso más en la cobertura y utilizar formatos nativos de WhatsApp. Es por ello que, en lugar de mandar enlaces, se apoyaron en las notas de voz algo que, como vimos anteriormente, ya puso en práctica la BBC. El resultado fue más de 5.000 personas inscritas a este canal. Hasta el domingo de las elecciones, todo iba bien, pero ese domingo pasará a la historia de la redacción de Eldiario.es como el día de "la desesperación de WhatsApp". $Y$ es que "el volumen de altas era tan intenso que resultaba imposible hacer el flujo sin que las altas pendientes dejaran de acumularse". Además, cuando comenzó el servicio de envío de alertas, las reacciones en modo chat hicieron crecer el número de chats pendientes, lo que se tradujo en una saturación del propio móvil.

Además de Eldiario.es, en España también arranca su servicio de WhatsApp El Confidencial, y lo hace el 16 de abril de 2015 (elconfidencial.com, 2015). Este servicio lo ofrece tanto como medio de difusión, como de recepción de mensajes de los lectores. El funcionamento era similar al resto de experiencias en el envío de alertas informativas. Según hemos recogido en el cuestionario realizado por Alvaro Rigal, redactor jefe en El Confidencial, actualmente cuentan con 912 suscriptores. La medición la llevan a cabo a través de Google Analytics, y las alertas con información política son las que mejor les funcionan. La media de alertas diarias es de dos. Para Rigal, el servicio es muy poco práctico para medios, ya que el principal problema es que no permite hacer grupos grandes como Telegram, aunque cree que abrirán la posibilidad de listas grandes.

El último medio nacional nativo en sumarse al servicio es Diario Crítico (diariocrítico, s/d) que lanza el servicio el 6 de octubre de 2016, servicio que actualmente funciona de forma diaria. El resto de medios nacionales analizados como El Español, El País, El Mundo y La Razón, a pesar de utilizar otros servicios de mensajería como Telegram e incluso experiementar con Facebook Messenger, actualmente no utilizan WhatsApp para distribuir alertas informativas. 
De momento, y hasta que el volumen del tráfico y el propio proceso de distribución sea más ágil, solo utilizamos WhatsApp para la distribución a través de las botoneras", señala Pilar Millán, directora de desarrollo de audiencias en El País.

Para Laura Llamas, directora de investigación y marketing publicitário en La Razón, el principal problema del uso de WhatsApp para medios de comunicación es el desconocimiento.

\subsection{Grupo Zeta y otros medios locales}

El primer piloto del grupo Zeta se lleva a cabo en El Periódico de Catalunya, que lanza el servicio de alertas informativas el 30 de septiembre de 2015 .

"El proceso se inicia con una serie de conversaciones con el responsable de la nueva estrategia digital del grupo Zeta, Ricardo Villa. Esta persona, anteriormente, había sido el responsable del área multimedia de RTVE, con quienes habíamos conceptualizado varios proyectos. Estas conversaciones nos llevan a una necesidad clara que tenía El Periódico de distribuir la información relativa a unas elecciones locales", recuerda Antonio Gallo, CEO de Dogtrack.

A diferencia de las anteriores experiencias, este proceso sí que estaba automatizado. Para ello utilizaron la interface propia de Dogtrack y una API no oficial que conectaba con los servidores de WhatsApp. La medición del tráfico se hacía con la integración del acortador de Dogtrack en Analytics. El servicio se centró en la emisión de alertas informativas. La aplicación de mensajería se utilizaba para la distribución de contenidos mediante diferentes canales o secciones. Los usuarios enviaban palabras concretas como "Alta" o el nombre de la sección, por ejemplo, "Internacional", y quedaban suscritos a un buzón. Los envíos se realizaban según si los buzones o canales eran automáticos (todos los contenidos publicados en una sección determinada) o manuales (alertas informativas seleccionadas editorialmente por la redacción). La información política era la que mejor les funcionaba, aunque el principal problema con el que se encontraron fue "la oscuridad en cuanto a los datos y el comportamiento de los usuarios frente a la información distribuida".

Mediante este modelo, llegaron a tener hasta 15.000 suscriptores en menos de un año, pero se dejó de utilizar el servicio en ese mismo año. "Dejamos de utilizarlo debido al bloqueo constante del servicio por parte WhatsApp. Existían restricciones a nivel de número de suscriptores y WhatsApp bloqueaba los números de teléfono impidiendo la distribución de contenidos a los usuarios. Éstos nunca se daban cuenta de la baja del servicio, por lo que dábamos la imagen de que no funcionaba", recuerdan Francesc Pallarès, jefe de producto digital y Xurxo Martínez, jefe de contenidos digitales de El Periódico.

La reflexión tras esta experiencia muestra que, tal y como señala Antonio Gallo, a pesar de que WhastApp puede ser un canal perfecto para comunicar a los usuarios noticias relevantes, técnicamente no está preparado, y no lo está porque "no han querido". A esta misma reflexión también llega Antonio Rull de Eldiario.es y el impulsor del proyecto del Extra de Brasil. "Hasta el anuncio de la apertura de WhastApp Empresas, ellos no han querido que medios de comunicación lo utilicen como canal de distribución. Ahora queda esperar que hagan las mejoras oportunas para que las organizaciones o medios puedan apoyarse en ellos", concluye Gallo.

A pesar de las limitaciones, tras estas experiencias, se siguen sumando más periódicos. El 13 de septiembre de 2016, La Gaceta de Salamanca lanza su servicio de alertas (La Gaceta de Salamanca, 2016); el 6 de febrero de 2017, Diario de Jaén (Diario Jaén, 2017) y el 12 de marzo de 2017 ABC Sevilla (ABC, 2017).

Tal y como señala David Varona, el impacto de la adopción de este servicio en los medios de información general abre nuevas vías para la distribución del contenido:

Si bien es cierto que las aplicaciones de mensajería no cambiarán el periodismo, sí que van a modificar la distribución. Obligará a plantear los temas de otra forma, adaptados a esta nueva distribución. Igual que ya hemos hecho con las redes sociales, habrá que pensar formatos y estructuras narrativas que encajen en la conversación con el chatbot o en la mensajería privada.

\subsection{Tipologías del uso de WhatsApp en los medios españoles}

A continuación, resumimos en la Figura 11 las principales experiencias del uso de WhatsApp en los medios impresos y diarios nativos en España en función del uso del canal.Un resumen por grupo de comunicación de los medios que sí han llevado a cabo algún tipo de experiencia en WhatsApp en los últimos cuatro años, nos muestra que Prensa lbérica es el medio de comunicación español que más está apostando por este canal. Así se refleja en la Figura 12.

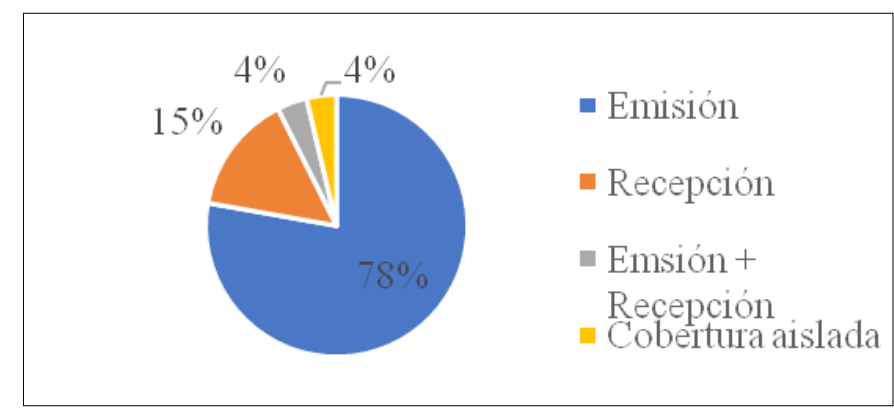

Figura 11. Principal uso de los medios impresos y diarios nativos que sí han utilizado WhatsApp. Elaboración propia. 


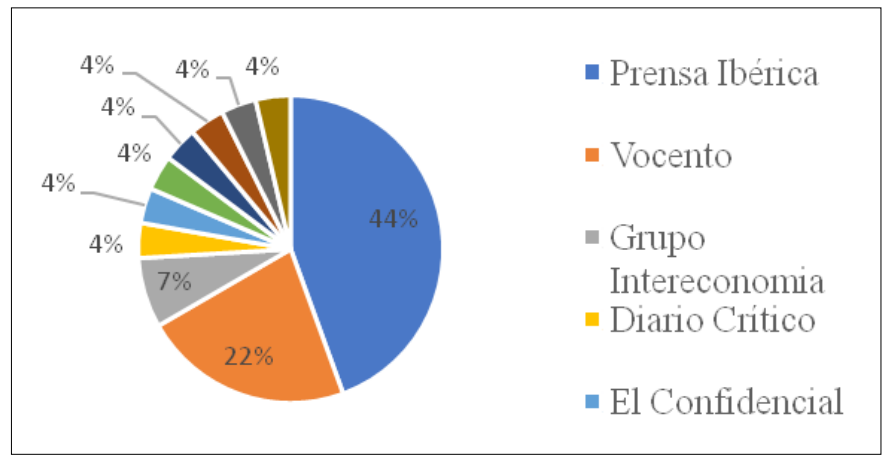

Figura 12. Grupos de comunicación españoles que más apuestan por WhatsApp. Elaboración propia.

\subsection{La experiencia de Prensa Ibérica}

La experiencia de Prensa Ibérica constituye un testimonio de primera mano para poder analizar cómo es el comportamiento del usuario y cómo es el consumo informativo en la plataforma de WhatsApp. Debido a que Prensa Ibérica es un grupo compuesto por periódicos locales muy heterogéneos, nos permite comparar realidades muy diferentes, lo que enriquece tremendamente este estudio.

Como señalamos anteriormente, el primer piloto se desarrolló en dos periódicos del grupo: Diario de Mallorca y Diario Información. Tal y como señala el informe interno del proyecto piloto facilitado por Prensa Ibérica exclusivamente para la realización de este estudio, en relación al lanzamiento del servicio en Diario de Mallorca, la previsión eran conseguir cerca de 300 contactos suscritos al servicio en el primer mes, una previsión bastante más ambiciosas que la de Oxford Mail, cuyo objetivo era llegar a los 500 suscriptores en el primer semestre. La respuesta de Mallorca fue mayor. "Tras la primera hora de salida, más de 50 personas ya se habían inscrito en este servicio. Al finalizar el día, el número de contactos agregados llegó a 233", recuerda Prensa Ibérica en su informe.

En seis meses, Diario de Mallorca consiguió 1.586 suscriptores y un promedio de conversión en tráfico del 8,16\% en sus envíos. Según recoge el informe, Prensa lbérica ya medía la rentabilidad económica del servicio teniendo en cuenta el ingreso por usuario único y haciendo un cálculo con la cantidad de tráfico recibido. También monitorizaba el tiempo medio para mandar un WhastApp a todas las listas de difusión, que por aquel entonces, era de unos 20 minutos por alerta. Cabe recordar que no existía la versión escritorio de la aplicación y tampoco una herramienta para acortar los enlaces e insertar los códigos de seguimento para Analytics, herramienta que hoy día sí tienen tras un desarrollo propio.

Respecto al contenido de las alertas enviadas en los primeros seis meses del servicio, destaca el tráfico recibido con un suceso de carácter internacional, que proporcionó una conversión por encima del 200\%.
Un avión que volaba entre Barcelona y Düsseldorf se estrella en Los Alpes http://bit.ly/1BKjKGV

Las métricas del informe piloto de Prensa Ibérica arrojan datos muy curiosos. Por ejemplo, el consumo informativo a través de las alertas de WhastApp no siempre es inmediato, es decir, encontramos casos en los que los suscriptores acceden al contenido informativo meses después del envío. Lo que muestra que el usuario de WhatsApp no borra los mensajes, es decir, que se va creando una especie de hemeroteca de alertas en su teléfono.

Actualmente el servicio de Diario de Mallorca cuenta con 3.065 suscriptores, es decir, crece un $41 \%$ en menos de dos años.

Después de esta experiencia, Prensa Ibérica replica el modelo en Diario Información y la demanda del servicio se triplica. Tras el primer día del lanzamiento del servicio en Alicante, se alcanzan más de 3.000 suscriptores, algo que, al igual que pasó con la experiencia de Eldiario.es, casi colapsa el terminal agregando los contactos. "WhatsApp es una buena vía de comunicación, pero las posibilidades que ofrece no están pensadas para la recepción y manejo de una gran cantidad de usuarios. Tanto la aplicación, como emuladores e incluso la versión escritorio, se bloquean constantemente", resume Fátima Martel, responsable de participación y redes sociales de Prensa Ibérica.

Pero no todos son problemas, Martel señala que es fácil convertir cada suscriptor en visita, ya que "el ratio de visitas generadas / número de suscriptores es alto". Y así lo demuestran los datos. Existen periódicos en Prensa Ibérica con este servicio cuyo ritmo de crecimiento mensual en términos de tráfico ronda el $40 \%$. Es el caso de Mallorca Zeitung, un semanario del grupo escrito en alemán.

Mallorca Zeitung lanzó el servicio el 6 de octubre de 2016. Actualmente cuenta con 1.820 suscriptores, una cifra que podríamos considerar modesta, pero el ratio de conversión en tráfico (que se puede medir) es sorprendente. Fátima Martel concluye:

La principal complejidad en la medición de visitas generadas desde WhastApp se encuentra en que no podemos medir las visitas cuando un usuario copia y pega un enlace en un grupo de amigos, por ejemplo. En la actualidad suele contar la visita como tráfico directo, no como social. Otra dificultad está en la imposibilidad de medir las visualizaciones de pantallazos de noticias, que tanto proliferan en este servicio de mensajería.

Respecto al número de suscriptores, la realidad depende de la fecha de lanzamiento del servicio y la localidad geográfica, pero oscila entre los 1.000 y los 6.000 suscriptores, dependiendo del medio. El ritmo de crecimiento mensual de los 
suscriptores nuevos está entre el 1\% y el 4\%, según el periódico. Es decir, es menor que el ritmo de crecimiento del tráfico recibido. Pero el dato más sorprendente es el bajo porcentaje de baja del servicio. "WhatsApp se convertirá en un canal más de fuentes de entradas. A medida que mejore la aplicación para la gestión de datos y recepción de contenido será muy potencial. Esto unido a la capacidad de cada medio de unirlo al data para la personalización del contenido, puede tener mucho recorrido. Aunque, uno de los principales retos será el no caer en el concepto de 'spam', y terminar como muchas campañas de mailing,", vaticina Martel sobre el futuro de la aplicación en los medios de comunicación.

\section{Conclusiones}

Aunque todos los medios consultados coinciden en que WhatsApp es un canal interesante, lo cierto es que los medios locales y periódicos nativos españoles son los que más están apostando por el uso de la aplicación como canal de distribución del contenido informativo a través de alertas. Eso sí, no sin dolores de cabeza derivados de la inoperatividad intencionada de la aplicación para gestionar grandes volúmenes de mensajes y contactos.

Tras las primeras experiencias, la audiencia española responde positivamente al servicio en términos de conversión en tráfico, muy por encima del recibido en Twitter e incluso de las newsletters, aunque todavía no podemos hablar de audiencias masivas.

La experiencia con mayor volumen de suscriptores la encontramos en El Periódico de Catalunya con 15.000 suscriptores, y fue por la automatización del proceso, que finalmente tuvieron que abandonar ante los bloqueos constantes de WhatsApp. El resto de experiencias, tanto en coberturas informativas concretas, como en el servicio de alertas, no superan los 6.000 suscriptores. Aunque también es verdad que todavía es un servicio relativamente reciente y desconocido para muchos lectores, e incluso para medios de comunicación. Y es que, a diferencia de otras redes sociales, un usuario de WhatsApp no puede tener constancia de la cuenta de un medio de comunicación mediante sugerencias o similitudes de comportamiento. Quizás lo más interesante es el acceso a nuevos públicos, especialmente a personas que utilizan WhatsApp, pero no internet, gracias a la sencillez en la estructura y en el diseño.

El consumo de la información en la plataforma invita a explorar nuevos formatos narrativos derivados de los patrones de consumo específicos de WhatsApp, como puede ser el hecho de que el lector accede al contenido informativo de las alertas hasta 30 días después de recibirlas, algo totalmente inédito hasta el momento y que no se produce en otras redes como Facebook o Twitter, ya que en estas redes sociales los algoritmos (Cruz, 2017) son los responsables de segmentar las publicaciones, cosa que en WhatsApp todavía no sucede. Este hecho abre nuevos caminos a la investigación para profundizar en el consumo informativo desde los dispositivos móviles.

Actualmente el gran problema de WhatsApp es la complejidad para medir el tráfico de la información distribuida dentro la aplicación. Para los medios de comunicación bastaría con lo que podríamos llamar el "WhatsApp Analytics", un recurso estadístico que ya ofrecen las redes sociales para medir el tráfico de los contenidos distribuidos, así como la integración con Google Analytics. Por otro lado, las aplicaciones de mensajería privada están ocultando buena parte de la conversación que antes estaba en Twitter o Facebook, por lo que el gran reto para los medios de comunicación españoles es buscar la forma de reconducir esta conversación a entornos más abiertos. En esta línea trabaja actualmente la empresa española Dogtrack, quien, teniendo en cuenta que trabajan bajo los requisitos de la aplicación, pueden integrar contenido multimedia desde WhatsApp mediante flujos de curación seguros y sistematizados en televisiones, radios y medios digitales.

El futuro del uso de la aplicación para los medios de comunicación estará supeditado a la decisión de apertura (o no) que WhatsApp decida hacer. Y es que, las limitaciones de la aplicación no responden a muros tecnológicos, sino a muros estratégicos, es decir, si WhatsApp quisiera, levantaría las restricciones a los medios de comunicación. Y con este levantamiento es muy probable que apareciera un puesto necesario en la compañía: Responsable de las relaciones con los medios de comunicación, como ya existe en Facebook o Twitter. Hasta entonces, Facebook seguirá controlando la conversación pública y, al ser propietario de WhatsApp, también la conversación privada de los medios de comunicación con sus audiencias.

\section{Referencias}

ABC (2017). Conecta con ABC de Sevilla vía WhatsApp. ABC Sevilla, 12/05/2017. Recuperado de http://sevilla.abc.es/sevilla/sevi-conecta-abc-sevilla-whatsapp-201705121144_noticia.html

Aguado, J.M., Feijóo, C, y Matínez, I. J. (2013). La Comunicación Móvil: Hacia un nuevo ecosistema digital. Barcelona: Editorial Gedisa S.A

Barot, Trushar (2014). How BBC News covered Indian elections on WhatsApp and WeChat. BBC blogs, 22/07/2014. Recuperado de http://www.bbc.co.uk/blogs/collegeofjournalism/entries/b2b67bf813ce-3acb-9a29-c9680cc77c9e

Barot, Trushar (2015). How BBC Ebola WhatsApp service is battling virus and finding great stories. BBC blogs, 22/07/2014. Recuperado de http://www.bbc.co.uk/blogs/collegeofjournalism/entries/ Of944ab7-9f96-4091-a927-db826630d997

BBC Media Center (2014). Instant messaging trial launches on BBC's International News services. BBC. About the BBC, 04/04/2014. Recuperado de http://www.bbc.co.uk/mediacentre/worldnews/bbc-international-news-messaging

Calero Vaquera, M. L. (2014). El discurso del whatsapp: entre el messenger y el SMS, Oralia, 17, 87-116. 
Catalina-García, B. (2015). Jóvenes y consumo de noticias a través de Internet y los medios sociales. Historia y Comunicación Social, 20(2), 601-619.

Channel 4 News (2014). Follow Channel 4 News on WhatsApp and Snapchat. Channel 4 News, 13/11/2014. Recuperado de https://www. channel4.com/news/follow-channel-4-news-on-whatsapp-andsnapchat

Cruz, A. (2017). Cómo funcionan los algoritmos de Facebook, Instagram y Twitter. Blog de Marketing Digital de Resultados. Recuperado de https://www.rdstation.com/blog/es/algoritmo-redes-sociales

DiarioCrítico (s/d). Reciba gratis en su móvil las noticias del día en WhatsApp. Diariocrítico. Recuperado de https://www.diariocritico. com/noticias-del-dia-diariocritico-y-telegram

Diario Jaén (2017). Conecta con Diario JAÉN vía WhatsApp. Diario JAÉN, 06/02/2017. Recuperado de http://www.diariojaen.es/interno/ conecta-con-diario-jaen-via-whatsapp-EF2557644

Efecto Cocuyo (2015). Efecto Cocuyo: primer medio venezolano con canal WhatsApp para el periodismo ciudadano. Efecto Cocuyo, 05/08/2015. Recuperado de http://efectococuyo.com/apoyo-al-periodismo/efecto-cocuyo-primer-medio-venezolano-con-canal-whatsapp-para-el-periodismo-ciudadano

elconfidencial.com (2015). Nos leemos en WhatsApp. elconfindencial. com, 16/04/2015. Recuperado de https://blogs.elconfidencial.com/ comunicacion/en-contacto/2015-04-16/nos-leemos-en-whatsapp_761246/

eldiario.es (2015). Qué aprendimos usando WhatsApp y Telegram durante el 20D. eldiario.es, el blog de la redacción, 21/12/2015.

Recuperado de http://www.eldiario.es/redaccion/aprendimos-usando-WhatsAppTelegram_6_465163516.html

EXTRA (2013). EXTRA cria novo canal de comunicação com o leitor no WhatsApp: adicione e participe. Extra, 24/06/2013. Recuperado de : https://extra.globo.com/noticias/extra-cria-novo-canal-de-comunicacao-com-leitor-no-whatsapp-adicione-participe-8799400.html

EXTRA (2014). EXTRA lança rede para conectar jornalistas da América Latina que cobrem o narcotráfico. Extra, 03/06/2014. Recuperado de https://extra.globo.com/noticias/mundo/extra-lanca-rede-para-conectar-jornalistas-da-america-latina-que-cobrem-narcotrafico-12699248.html

Flamarch, J. (06/07/2014). ¿Puede Whatsapp ayudarnos a conectar con los lectores?. Recuperado de http://jflamarich.com/experiencias/ puede-whatsapp-ayudarnos-a-conectar-con-los-lectores

Frankenhauser, N. (2015). Webinar recap: How the BBC is using Whats App to boost engagement. World News Publishing Focus, WAN-IFRA, 29/07/2015. Recuperado de https://blog.wan-ifra.org/2015/07/29/ webinar-recap-how-the-bbc-is-using-whatsapp-to-boost-engagement

Gutiérrez-Rubí A. (2015). La política en tiempos de WhatsApp. Madrid: El País Llbros.

Jarvis, J. (2015). El fin de los medios de comunicación de masas. ¿Cómo serán las noticias del futuro? Barcelona: Gestión 2000.

La Gaceta de Salamanca (2016). Lagacetadesalamanca.es, ahora en tu WhatsApp. La Gaceta de Salamanca, 12/09/2016. Recuperado de http://www.lagacetadesalamanca.es/salamanca/2016/09/12/lagacetadesalamancaes-ahora-whatsapp/184927.html

Martín, R. (2016). La conversación guasap, Soprag, 4(1), 108-134.

Miller, C., y Jones, J. (2014). Firestone and the Warlord. The untold story of Firestone, Charles Taylor and the tragedy of Liberia. ProPu- blica, 18/11/2014. Recuperado de https://www.propublica.org/ article/firestone-and-the-warlord-intro

Newman, N. (2016). Journalism, Media, and Technology trends and predictions 2017. Oxford: RISJ.

Parris, T. (2014). Talk To Us About Our Firestone Investigation on WhatsApp. ProPublica, 17/11/2014. Recuperado de https://www. propublica.org/getinvolved/talk-to-us-about-our-firestone-investigation-on-whatsapp

Quiroz Pacheco, Y.R. (2015). Aplicación del Whatsapp en el periodismo digital y ciudadano, Hamut'ay, 2(1), 71-83.

Ramalho, G. (2014). Brazilian newspaper Extra celebrates one year using WhatsApp to connect reporters and readers. Knight Center for Journalism in the Americas, 27/06/2014. Recuperado de: https://knightcenter.utexas.edu/blog/00-15670-brazilian-newspaper-extra-celebrates-one-year-using-whatsapp-connect-reporters-and-rea

Rodríguez, P. (2016). Paul Steiger: "El móvil es el futuro para la información y el entretenimiento". El Mundo, 28/01/2016. Recuperado de http://www.elmundo.es/television/2016/01/28/56a91fd1268e3e40468b4717.html

Romero, J., y Perlado, M. (2015). El fenómeno WhatsApp en el contexto de la comunicación personal: una aproximación a través de los jóvenes universitarios. Icono 14, 13, 73-94.

Rosales, A., Fernández-Ardévol, M. (2016). Beyond WhatsApp: Older people and smartphones. Romanian Journal of Communication and Public Relations, 18, (1), 27-47.

Rull, A. (2015). Algunas ideas sobre el uso de Whatsapp para coberturas informativas. eldiario.es, 15/04/2015. Recuperado de http://www.eldiario.es/redaccion/Whatsapp-castigo-medios_6_377672245.html

Sandeman, G. (2015). Oxford Mail's WhatsApp news service tops 1,200 subscribers after six months. The Guardian, 09/01/2015. Recuperado de https://www.theguardian.com/media/media-blog/2015/ jan/09/oxford-mails-whatsapp-news-service-tops-1000-subscribers-after-six-months

Sanmartín-Sáez, J. (2007). El chat. La conversación tecnológica, Madrid: Arco / Libros.

Shirky, C (2012), Excedente Cognitivo. Creatividad y generosidad en la era conectada. Barcelona: Deusto.

Vaquera, M. L. C. (2014). El discurso del WhatsApp: entre el Messenger y el SMS. Oralia, 17, 85-114.

Vela, C., y Cantamutto, L. (2016). De participante a observador: el método etnográfico en el análisis de las interacciones digitales de Whatsapp. Tonos digital, (31), 1-21.

WhatsApp (s/d). FAQ. Recuperado de https://faq.whatsapp.com/ general $/ 26000052$ ? lg=enctc=US\&lang=es

\section{CV}

Fátima Fares Medina. Es periodista e investigadora en la Universidad Complutense de Madrid, donde actualmente realiza su tesis doctoral "Periodismo Transmedia en el entorno móvil y en las redes sociales", dirigida por Jesús Miguel Flores Vivar.

Licenciada en Historia y Comunicación Audiovisual por la Universidad de Granada, Fátima obtuvo el Certificado de Sufi- 
ciencia Investigadora en la Universidad de Málaga.

Actualmente ocupa el cargo de directora de eventos en Prensa Ibérica, donde es responsable de crear narrativas y experien- cias emocionales en formato de evento. Especialista en el entorno móvil y las redes sociales, ocupó el cargo de directora de redes sociales en Prensa Ibérica.

\section{MÁSTER UNIVERSITARIO ONLINE EN OCUMENTACIÓN DIGITAL} DISEÑA, CREA, GESTIONA, EVALÚA, COMPARTE Y PROMOCIONA RECURSOS DIGITALES

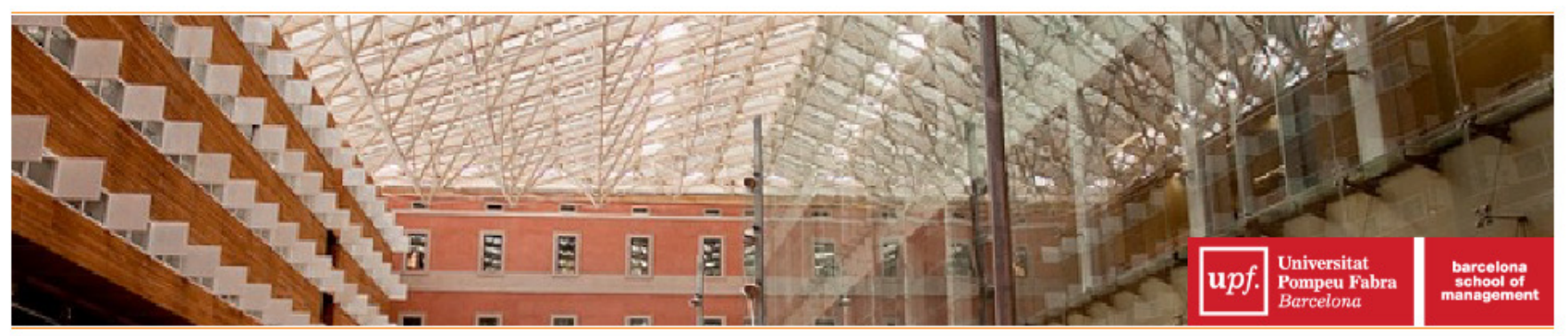

\section{MASTER EN USABILIDAD, DISEÑO DE INTERACCIÓN Y EXPERIENCIA DE USUARIO (ONLINE)}

MÁSTER EN UX

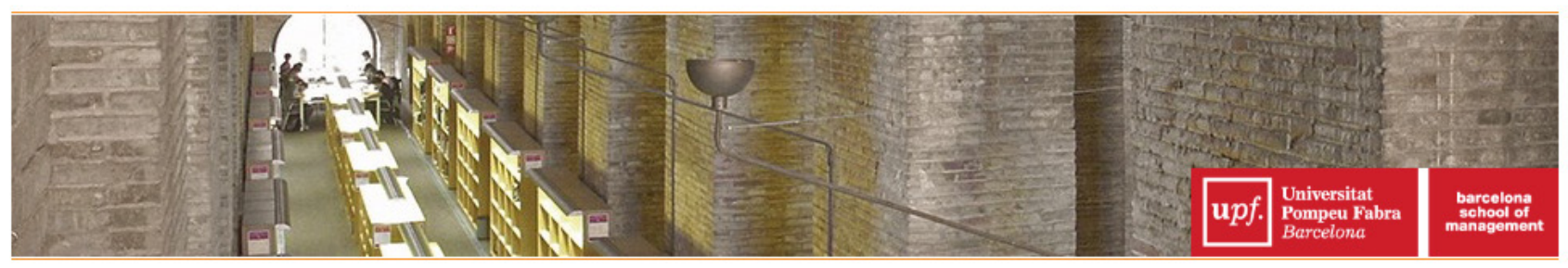

\section{MÁSTER EN BUSCADORES}

MARKETING (SEM) · POSICIONAMIENTO (SEO) . ANALYTICS . SOCIAL MEDIA

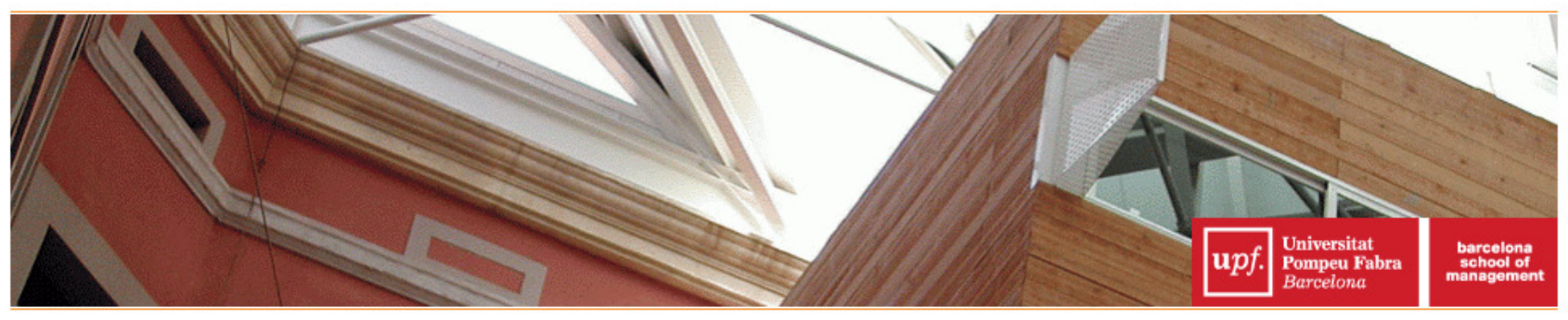

